\title{
KOMPARASI LEVENBERG-MARQUARDT (LM) DENGAN BROYDEN, FLETCHER, GOLDFARB, AND SHANNO QUASI-NEWTON (BFGS) BPNN UNTUK DIIMPLEMENTASIKAN PADA DATA KECEPATAN ANGIN
}

\author{
Fakultas Teknologi Informasi \\ Universitas Islam Kalimantan Muhammad Arsyad Al Banjari Banjarmasin \\ Haji Sirajuddin \\ Uniska.siraj@gmail.com
}

\begin{abstract}
ABSTRAK
Penelitian ini dilakukan untuk mengkomparasi Levenberg-Marquardt (Lm) Dengan Broyden, Fletcher, Goldfarb, And Shanno Quasi-Newton (Bfgs) pada Penerapan Backpropagation Neural Network $(B P N N)$ untuk memprediksi data Kecepatan Angin rata-rata. Data yang digunakan pada penelitian ini adalah data kecepatan angin rata-rata harian pada bulan Januari 2010 sampai Desember 2014 di Banjarbaru, Kalimantan selatan . Kecepatan angin ditentukan oleh perbedaan tekanan udara antara tempat asal dan tujuan angin dan daerah yang dilaluinya, Prediksi salah satu teknik yang paling penting dalam mengetahui kecepatan angin yang dihasilkan. Hasil Komparasi analisis Levenberg-Marquardt (Lm) Dengan Broyden, Fletcher, Goldfarb, And Shanno QuasiNewton (Bfgs) menunjukkan bahwa Pada penelitian ini hasil terbaik yang didapatkan menggunakan Levenberg Marquardt (trainlm) dengan akurasi sebesar 95,93\%, setelah dibandingkan dengan performance maksimum dari algoritma BPNN yang lain. model BPNN merupakan metode terbaik yang digunakan untuk prediksi kecepatan angin ratarata harian dengan nilai RMSE sebesar 1,3378.
\end{abstract}

Kata kunci : Kecepatan Angin, Backpropagation Neural Network, Broyden, Fletcher, Goldfarb, And Shanno Quasi-Newton, Levenberg-Marquardt

\section{PENDAHULUAN}

Untuk melakukan prediksi secara akurat, diperlukan metode yang tepat pula. Neural network atau biasa disebut juga jaringan syaraf tiruan adalah suatu metode komputasi yang dapat digunakan untuk memprediksi. Cuaca adalah keadaan udara pada saat tertentu dan di wilayah tertentu yang relatif sempit dan pada jangka waktu yang singkat (Sarjani, 2009). Unsur cuaca yang menentukan dalam penerbangan salah satunya adalah kecepatan angin. Angin menentukan orientasi terbaik landas pacu agar pesawat terbang dapat lepas landas dan mendarat dengan selamat, karenanya informasi mengenai arah dan kecepatan angin rata-rata sangat dibutuhkan oleh para penerbang dalam kebutuhan perencanaan penerbangan. Selain itu Pemanfaatan tenaga angin sebagai sumber kecepatan angin digunakan dengan sebuah generator listrik, alat ini berfungsi untuk mengumpulkan energi dari angin. proses pemanfaatan ini yaitu dengan mengubah rotasi dari pisau turbin menjadi arus listrik. Alat ini berfungsi untuk mengumpulkan energi dari angin. Proses pemanfaatan ini yaitu dengan mengubah rotasi dari pisau turbin menjadi arus listrik. Dengan mengetahui predikisi berapa besar kecepatan angin yang dihasilkan tiap jam atau bahkan tiap menitnya, besarnya kecepatan angin yang dihasilkan dapat menghitung dengan jumlah kebutuhan listrik sehingga kebutuhan akan memprediksi atau meramalkan kecepatan angin adalah 
sangat penting. Melihat kebutuhan akan prediksi untuk mengelola sumber daya angin khususnya sumber daya energi angin menjadi faktor penting untuk menghitung jumlah listrik yang dihasilkan dari energi angin ini maka mengharuskan penggunaan modelmodel khusus untuk dapat memprediksi kecepatan angin baik kecepatan angin jangka pendek maupun kecepatan angin jangka panjang untuk memproduksi listrik tersebut. Prediksi adalah salah satu teknik yang paling penting dalam mengetahui kecepatan angin yang dihasilkan. Keputusan memprediksi sangatlah penting, karena dengan prediksi dapat menghitung jumlah yang dihasilkan dengan jumlah prediksi yang baik adalah prediksi secara akurat.

Berdasarkan latar belakang permasalahan yang telah disebutkan dalam uraian sebelumnya, dapat dirumuskan permasalahan, apakah model prediksi dapat memprediksi kecepatan angin guna mengetahui besar daya listrik yang dikeluarkan. Model Neural Netwrok sebagai algoritma yang dapat memprediksi diharapkan dapat memprediksi besar kecepatan angin tersebut. Cuaca adalah keadaan udara pada saat tertentu dan di wilayah tertentu yang relatif sempit dan pada jangka waktu yang singkat (Sarjani, 2009). Beberapa penelitian mengenai pemodelan dan peramalan kecepatan angin baru-baru ini telah dilakukan dengan menggunakan metode ANFIS. Johnson, Negnevitsky dan Muttaqi (2007) menggunakan data kekuatan angin untuk kebutuhan listrik di Australia. Sedangkan Castellanos dan James (2009) mengeksplorasi teknik peramalan tenaga angin untuk memprediksi rata-rata kecepatan angin rata-rata harian dimana kecepatan angin dimodelkan berdasarkan variabelvariabel lain yang berkorelasi dengan kecepatan angin seperti tekanan udara dan temperatur udara. Zhou, Huang dan Wu (2009) menggunakan ANFIS untuk meramalkan kecepatan angin di pulau Mauii, Hawai. Hasilnya adalah ANFIS menghasilkan ketepatan peramalan yang baik dan dapat menyelesaikan masalah non-linier pada karakteristrik data kecepatan angin.

Pada penelitian ini data yang digunakan adalah data kecepatan angin rata-rata harian (knots) periode bulan Januari 2010 sampai Desember 2014 yang diperoleh dari Badan Meteorologi, Klimatologi dan Geofisika (BMKG) Banjarbaru. Kecepatan angin dipengaruhi oleh dua variabel yang paling utama yaitu tekanan udara dan temperatur udara. Angin terbentuk karena adanya perbedaan temperatur dan tekanan udara. Karena terdapat hubungan antara kecepatan angin ratarata harian dengan tekanan udara dan temperatur udara.

Untuk mengetahui keakuratan dari Algoritma BPNN, dari hasil prediksi algoritma BPNN diharapkan dapat diperoleh model terbaik untuk prediksi kecepatan angin rata-rata harian dengan kriteria RMSE (Root Mean Square Error) yang terkecil.

\section{RUMUSAN MASALAH}

Berdasarkan uraian latar belakang, maka permasalahan yang dapat dikaji dalam penelitian ini adalah :

1. Bagaimana pemodelan kecepatan angin rata-rata harian di kota Banjarbaru menggunakan algortima BPNN dengan variabel input kecepatan angin.

2. Bagaimana pemodelan kecepatan angin kota Banjarbaru menggunakan algoritma BPNN dengan input hasil dari kecepatan angin. 


\section{TUJUAN PENELITIAN}

Tujuan yang ingin dicapai dalam penelitian ini adalah sebagai berikut:

Memodelkan kecepatan angin rata-rata harian kota Banjarbaru dan sekitarnya menggunakan algoritma BPNN dengan variabel input kecepatan angin.

\section{TARGET LUARAN DAN MANFAAT PENELITIAN}

untuk target luaran yang ingin dicapai yaitu bisa masuk ke Jurnal UNISKA kemudian bisa dilanjutkan ke Jurnal Nasional. Untuk Manfaat yang diharapkan yaitu : dengan adanya penelitian untuk Hasil penelitian ini diharapkan dapat menambah dan mengembangkan wawasan keilmuan dan pengetahuan mengenai algortima BPNN yang diterapkan pada data kecepatan angin. Sedangkan manfaat bagi pengguna penelitian, hasil penelitian ini dapat digunakan oleh Badan Meteorologi Klimatologi dan Geofisika (BMKG) sebagai informasi yang bertujuan untuk memberikan pelayanan meteorologi, klimatologi, kualitas udara, dan geofisika yang handal sehingga mendukung keselamatan dan keberhasilan pembangunan nasional serta berperan aktif pada bidang penerbangan, pelayaran, lingkungan hidup, penanggulangan bencana alam maupun bidang konstruksi. Disamping itu dapat membantu pemerintah daerah untuk memanfaatkan tenaga angin untuk membangun kincir angin yang nantinya akan di gunakan untuk pompa air di irigasi sekitar riam kanan dan riam kiri untuk mengairi irigasi pertanian dan pembangkit listrik tenaga angin yang masih dalam perancanaan pemerintah setempat untuk menambah pasokan listrik PLN di daerah Kalimantan selatan yang tiap tahunnya menyusut

\section{METODE PENELITIAN}

Ada beberapa algotrima yang dapat dipakai untuk memprediksi Kecepatan angin namun belum diketahui algoritma manakah yang memiliki kinerja lebih akurat. Sehingga perlu masing-masing algoritma diuji untuk mengetahuinya. Metode yang diusulkan adalah metode perbandingan tingkat akurasi dari algoritma yangbisa digunakan untuk prediksi data rentet waktu. yang digunakan untuk memprediksi data arus lalu lintas jangka pendek. Algoritma akan implementasikan dengan menggunakan Matlab. Backrpogation Neural Network yang dioptimalkan akan memiliki minimum error untuk setiap traning data yang diberikan. Penelitian ini dilakukan untuk mengkomparasi Levenberg-Marquardt (Lm) Dengan Broyden, Fletcher, Goldfarb, And Shanno Quasi-Newton (Bfgs) pada Penerapan Backpropagation Neural Network (BPNN) untuk memprediksi data Kecepatan Angin rata-rata

\section{ANALISA HASIL DAN PEMBAHASAN}

1. Hasil Penelitian

Algoritma yang diusulkan dalam penelitian ini akan di tetapkan pada data kecepatan angin tahun 2010-2014 di kota Banjarbaru Provinsi Kalimantan Selatan. Data Tahun 2010- 2012 dipergunakan sebagai training data 2013 digunakan sebagai data testing dengan Matlab.

Hasil dari percobaan di Matlab sebagai berikut : 


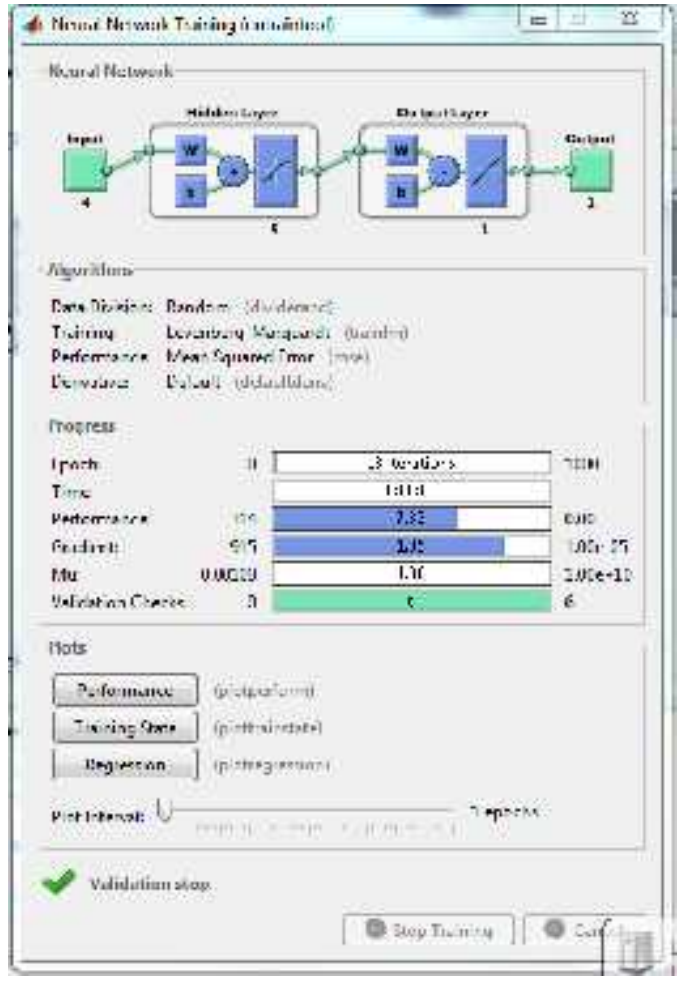

Gambar Neural Network

\section{Training (nintrainingtool) input 4}

Gambar diatas merupakan hasil priview dari tampilan bar training tool yang dari Backpropagation Neural Network pada saat melakukan proses training data dengan inputan 4 dan train $\mathrm{lm}$, dan hasilnya dapat dilihat pada gambar dibawah ini :

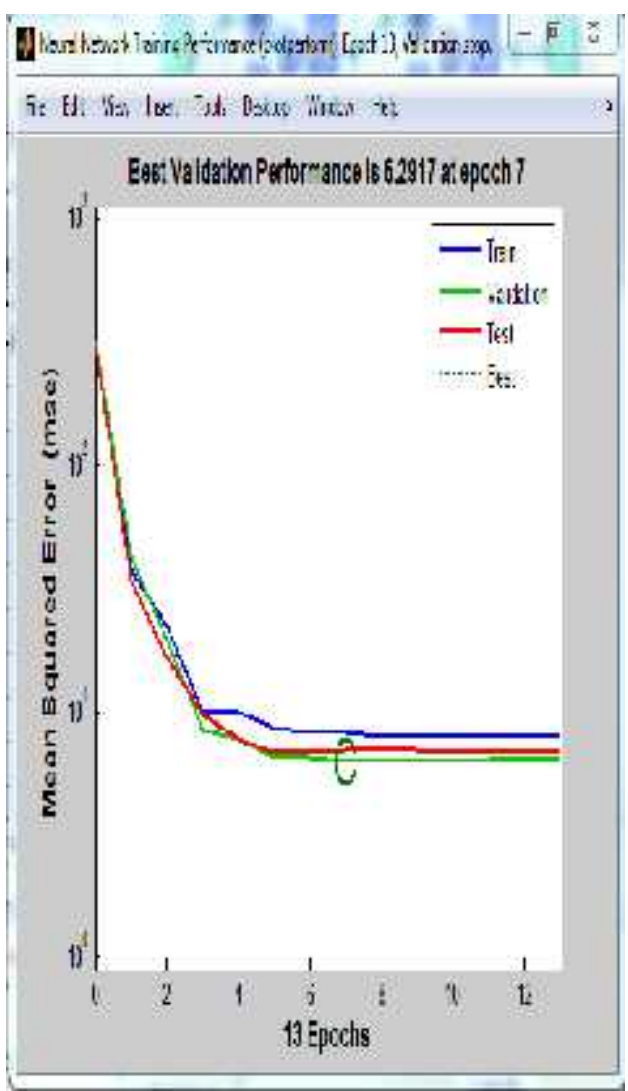

\section{Gambar Performance (plotperform) input 4}

Berdasarkan grafik diatas, diperoleh hasil training $1 \mathrm{~m}$ dengan inputan 4 menggunakan matlab untuk hasil pengujian Backpropagation Neural Network menghasilkan grafik training state dan performance MSE. 


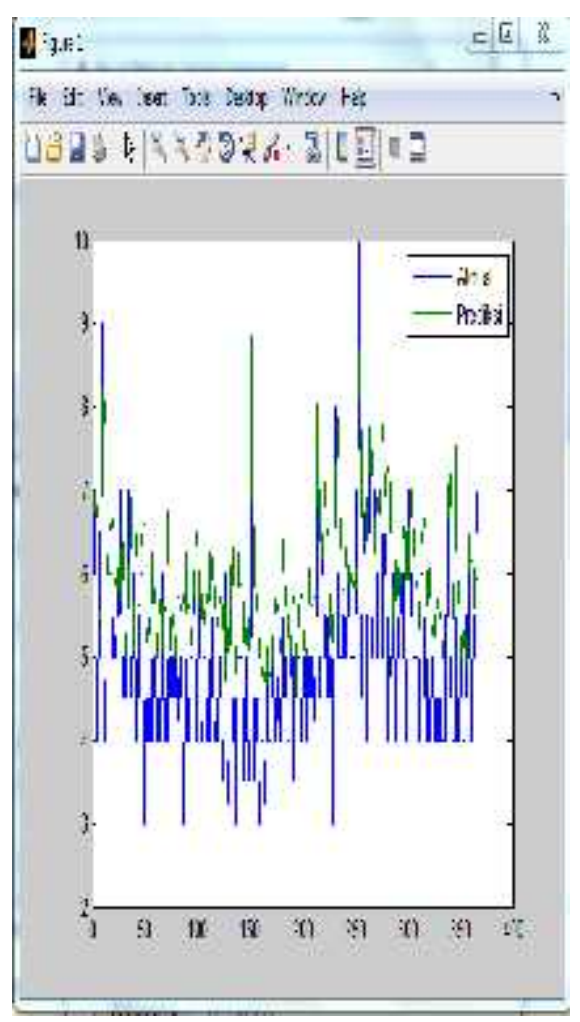

\section{Gambar Figure input 4}

Data training dan data Testing, dengan penambahan fitur input dan output Kecepatan angin terhadap titik uji. Proses pengujian struktur input 4 dengan menggunakan Training Levenberg Marquardt (LM).

\begin{tabular}{|c|c|c|c|}
\hline \multicolumn{4}{|l|}{ Norkasace } \\
\hline \multicolumn{4}{|c|}{ 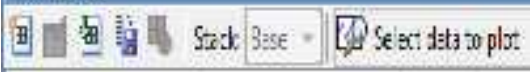 } \\
\hline lare = & Velue & $\mathrm{Mr}$ & MEx \\
\hline Q $E$ EF:N & 4 astuonts? & & \\
\hline EchSHE & $1 ; x s$ & $15 x$ & $56 x$ \\
\hline Einde: & ¿365 drubles & : & 305 \\
\hline Eitesing & 4:365 druble & $i$ & 30 \\
\hline 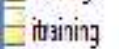 & cti1ta cales & : & $2 \pi$ \\
\hline (9) re: & (11 netrorts & & \\
\hline Etestro & ¿365 Jouble & $i$ & 20 \\
\hline Etrarre & ¿alto caie? & : & $\eta$ \\
\hline Ey & (B) $35 \mathrm{~J}$ Juble & 4573 & 33022 \\
\hline
\end{tabular}

\section{Gambar Workspace input 4}

Dari gambar di atas memberikan informasi bahwa RMSE sebesar 1.5096

\section{Implikasi Penelitian}

Berdasarkan hasil penelitian dan pengukuran, penerapan algoritma Backprogation Neural Network adalah algoritma yang memprediksi kecepatan angin rata-rata dengan lebih akurat. Dengan demikian, adanya penerapan algoritma Backprogation Neural Network mampu memberikan solusi bagi BMKG maupun instansi terkait, serta Hasil Penelitian ini bisa digunakan untuk penelitian yang berikutnya.

\section{Spesifikasi Perangkat Keras dan Perangkat Lunak \\ Kebutuhan Perangkat Keras}

Perangkat keras yang dibutuhkan untuk menguji Data set berupa Image $\mathrm{X}$-ray yaitu:

1. Processor Intel/Amd dengan kualitas bagus minimal Dual Core atau lebih sehingga perform aplikasi bekerja dengan lancer dan baik.

2. Memory $1 \mathrm{~GB}$ atau lebih

3. VGA Card minimal $64 \mathrm{Mb}$

4. Hardisk $256 \mathrm{~Gb}$ atau Lebih

5. Monitor dengan resolusi minimal 1024 x 768

Mouse dan Keyboard

Adapun perangkat lunak (software) yang digunakan untuk menjalankan aplikasi ini adalah sebagai berikut :

1. Sistem Operasi adalah Microsoft Windows 7 Ultimate, 8 , 10

2. MatLab R2013a

3. Microsoft excel/word untuk pembuatan table perbandingan data set

\section{PENUTUP}

Kesimpulan

Dari hasil penelitan dapat disimpulkan : Penerapan Algoritma Backpropagation Neural Network untuk prediksi 
membutuhkan waktu yang tidak sedikit karena perlu melakukan banyak percobaan dalam menetapkan jumlah input data, jumlah neuron dalam hidden layer, penentuan besarnya learning rate, menguji dengan fungsi pelatihan serta menerapkan teknik pembelajaran pada jaringan yang terbentuk. Pada penelitian ini hasil terbaik yang didapatkan menggunakan Levenberg Marquardt (trainlm) dengan akurasi sebesar $95,93 \%$, setelah dibandingkan dengan performance maksimum dari algoritma BPNN yang lain.

Dengan melakukan secara maksimal neural network dan kombinasi struktur yang dihasilkan saat ini belum dapat dikatakan sebagai hasil terbaik. Neural network memiliki hasil yang lebih baik dalam mengurangi kesalahan yang terjadi akibat adanya perubahan mendadak pada data, seperti terlihat pada perbandingan plot yang dihasilkan, walaupun terkadang MSE-nya tidak lebih baik setelah diuji dengan beberapa fungsi pelatihan yang ada didalam algoritma BPNN. Untuk tiap-tiap input yang akan ditetapkan hendaknya perlu pengamatan, analisa bobot serta bias agar mendapatkan hasil yang maksimal. Dalam mempercepat proses kalkulasi signifikansi input yang tinggi akan membantu jaringan sehingga dapat menghemat waktu.

\section{Saran}

Berdasarkan kesimpulan di atas, maka ada beberapa saran yang dapat disampaikan :

1. Untuk menghasilkan prediksi yang lebih baik diperlukan data inputan yang lebih banyak.

2. Perbanyak pelatihan hingga mendapatkan input, hidden layer yang menghasilkan error sekecil - kecilnya.

\section{DAFTAR PUSTAKA}

R. H. Kusumodestoni and A. K. Zyen, "Prediksi kecepatan angin dengan model neural network," Prediksi, vol. 6, no. 1, p. 7, 2015.

S. D. Permai and N. Iriawan, "Pemodelan Kecepatan Angin Rata-Rata," Kecepatan Angin, vol. 1, no. 2, p. 4, 2013.

S. Mujiasih, "Pemanfatan Data Mining Untuk Prakiraan Cuaca," no. September 2011, pp. 189-195.

C. Dewi, D. P. Kartikasari, and Y. T. Mursityo, "Prediksi Cuaca Pada Data Time Series Menggunakan Adaptive Neuro Fuzzy Inference System ( Anfis )," vol. 1, no. 5, pp. 18-24, 2014.

K. Gobakis, D. Kolokotsa, A. Synnefa, M. Saliari, K. Giannopoulou, and M. Santamouris, "Development of a model for urban heat island prediction using neural network techniques," Sustain. Cities Soc., vol. 1, no. 2, pp. 104-115, 2011.

S.Mandal, "Prediction of tides using back-propagation neural networks," Backpropagation, vol. 1-6, no. Penerapan Backpropagation, p. 6, 2001.

A. Fadholi, "Analisis Data Arah Dan Kecepatan Angin Landas Pacu ( Runway ) Menggunakan Aplikasi Windrose Plot ( Wrplot )," Anal. data Arah dan Kecepatan Angin, vol. 9, no. September, pp. 84-91, 2013.

J. A. P. K. Angin, "Kata Kunci :," Kecepatan Angin, vol. 8535, no. 
Alat Pengukur Kecepata Angin, 2009.

R. Dewi, A. Pratomo, and Y. V. Jaya,

"Kecepatan Angin Pada Zona Alur Pelayaran Wave height estimation based on the wind speed zona waters Tanjungpinang shipping channel," Estim. based one Wind Speed Zo. Waters, vol. 2, no. 1999, p. 6, 2010.

D. T. T. M. E. S. Maya Azlina, "Pembuatan Alat Ukur Kecepatan Angin," Alat Ukur, vol. 8535, no. Alat ukur kecepatan Angin, p. 13, 2013. 